\title{
13 Can China Achieve Green Growth?
}

Yongsheng Zhang

\section{Introduction}

In 1978, after over 100 years of decline, China embarked on a journey to restore its status as the world's largest economy. From the early 1500s until the early 1800s, China's economy was the world's largest. By 1820, it accounted for one-third of the world's gross domestic product (GDP). The next two centuries, however, were tumultuous for China. The country experienced catastrophic decline between 1820 and 1950 and then, starting in 1978, it experienced meteoric rise (Maddison 2001). After reform and opening up in 1978, China started to catch-up with the western world with an average of 10 per cent annual growth rate over the past three decades. It now takes the second place in the world, with its per capita GDP increasing from US\$154 in 1978 to US\$6,060 in 2012. It is widely expected that around 2020, China's economy will overtake that of the United States and regain its first place in the globe if the economic boom continues, or even if it slows down a little. As such, China is likely to become a high-income society with per capita earning reaching the average level of the OECD by 2030 (WB/DRC 2013: 3).

Nonetheless, China faces unprecedented challenges resulting from its unsustainable traditional growth model, which is characterised by high resource consumption and severe environmental degradation. To successfully accomplish its modernisation, China must achieve the following two significant transformations. First, China must rebalance its development between economic and social undertakings, internal and external demands, urban and rural areas, as well as different regions. In this regard, China can draw on best practices from developed countries. Second, China has to take a green growth path that represents the future trend. The first transition, to a large extent, is an internal issue for China, while the second transition is a common issue shared by all nations of the world. China needs to make the two above transitions at the same time, as it is no longer feasible for China to achieve its modernisation target by simply continuing along the pathways previously taken by industrialised countries. China should jump over the current unsustainable development mode and instead directly modernise its economy in a green way, in order to be a frontrunner in international competition as it joins the high-income nations club. 
Green growth could play a significant role in China's modernisation. The barriers for China to achieve green growth do not stem from investment or technology, but instead from its distorted market system. China has unique advantages to achieve green growth and leapfrog to modernisation in a green way, but it also has many institutional obstacles to overcome. This chapter aims to identify the opportunities, advantages, barriers to, as well as the path for China to accomplish green growth. The second section introduces new thinking on how to understand green growth; the third section focuses on opportunities for green growth in China; the fourth section analyses the advantages and disadvantages of green growth in China; and, the fifth section elaborates upon the unfinished reforms aimed at achieving green growth in China.

\section{New Thinking on Green Growth}

\section{Understanding Green Growth in a New Way}

It's vital to understand green growth in a new way. Green growth is an unprecedented new development pattern which decouples growth from a heavy dependence on use of material resources, carbon emissions, and environmental damage, in order to promote growth through the creation of new green products markets, technologies, and investments, as well as changes in consumption and conservation behaviour. It is based on three key concepts. The first, that economic growth may be decoupled from rising greenhouse gas emissions and environmental degradation. Secondly, that the process of 'going green' can itself be a source of growth and, thirdly, that 'going green' is part of a virtuous circle which is mutually reinforcing with growth. Green growth is the means by which green development is achieved (WB/DRC 2013: 217). Green growth represents enormous opportunities and is the inevitable trend that China must follow. That said, the opportunities behind green growth are not evident to everyone. To comprehend the opportunities, a new thinking is needed.

First, it is difficult to understand the opportunities behind green growth in conventional industrialised thinking. Traditional industrialisation, which began with the Industrial Revolution, has been based on material resources input, and has been coupled with high carbon emissions, high-energy consumption and environmental damage. Consequently, 'going green' seems to contradict economic growth in nature and is bound to be a burden of growth. Some think green growth is merely an issue related to the need for energy efficiency improvement, renewable energy utilisation or cutting-edge technology development. This type of understanding of green growth is too narrow to fully recognise the opportunities behind it. 
Second, it is hard to understand green growth when using the analytical framework of marginal analysis focusing on optimising resource allocation in a given economic structure. Under a given economic structure, emission reduction is largely dependent on cutting resource input, and it seems to inevitably result in decreased output. In fact, 'going green' refers to changes that occur when an economic organisation jumps to a more competitive structure of division of labour, which is likely to accelerate economic development. According to Adam Smith (1776) and Allyn Young (1928), evolution of division of labour is the spring of economic growth. The insight was revived by Xiaokai Yang (2001) with inframarginal analysis, which is particularly powerful for investigating green growth driven by changes to economic structures.

A typical example may explain how the two misunderstandings above stop us from understanding green growth properly. A popular argument questioning green growth is that there does not exist sufficient evidence proving the feasibility of green growth. In this case, government is not convinced to take serious action in promoting green growth before sufficient evidence emerges. Nonetheless, the problem is that green growth is a self-fulfilling process, and the evidence and actions are interdependent. If the government does not take serious action on reducing emissions and protecting the environment, it is very hard for green growth evidence to become apparent. And this is the biggest dilemma for green growth. If the government and public take muscular action with confidence, then resources will be allocated in the green direction and the economy would jump from a non-green structure to a green structure, yielding green growth. Otherwise, economic development will never jump to the new model and instead it will lock on to the traditional non-green path. Nevertheless, the analytical framework of conventional marginal analysis fails to predict the inframarginal changes arising from the structure of division of labour.

It is difficult to fully understand the essence of green growth and see the opportunities behind it if green growth is understood in a traditional sense. Green growth perhaps represents the most profound and comprehensive transformation since the Industrial Revolution, and could bring about changes in all aspects of society including production, living, consumption, organisation and business models.

\section{New Context for Green Growth}

Aside from the new thinking, green growth can't be sufficiently understood unless it is put into the larger picture of new revolutions including the rapid development of information and communication technology (ICT), big data, new materials (like nano technology), or high-speed railway. In essence, the core of all the changes is the unprecedented improvement of transaction efficiency. 
As Smith (1776) pointed out, the spring of economic growth is the division of labour that is determined by the extent of the market, while the latter is determined by transaction efficiency. As Coase (1937) notes, the key to determine economic organisational structure is transaction efficiency. Specifically, the dramatic improvement of transaction efficiency is reflected as follows:

- Changes of information flow: Information dissemination is growing exponentially in terms of speed and content with the fast development of ICT, big data, and cloud data.

- Changes of people flow: People move much more conveniently and faster than ever before with the progress of high-speed railway, highways, aviation and the increased popularity of private cars.

- Changes of logistics: Transportation speed of goods is significantly boosted with quick and convenient logistics systems.

Consequently, the dramatic enhancement of transaction efficiency results in two outcomes, First, it gives birth to many new business, Second, it brings about many new business models or economic organisations. The function of entrepreneurs is to maximise profits through efficiently organising division of labour by using product market or factor market. With higher transaction efficiency, the room for businessmen to organise division of labour is largely expanded and a higher level of division of labour can be developed, which represents economic growth potential (Yang 2001).

In practical terms, the world is witnessing enormous changes that differ from those of traditional industrial society. The changes are not only to the context in which green growth develops, but the changes are themselves green growth.

First, the definition of resources is changing. Old resources may become valueless while some resources, previously seen as useless, may become valuable. For example, individual information is not valuable if it is scattered, but, once connected by ITC and big data, it forms part of an invaluable resource and, as a result, varieties of new business models appear (see examples such as Twitter and Facebook). Natural environment is another example. Due to underdevelopment, the ecological environment in poor regions is conserved and it now becomes a vital resource and can be translated into wealth. It's the same case for fossil fuel, which became more valuable during the Industrial Revolution.

Second, the business model is shifting. The function of entrepreneurs is to find the most efficient way to organise division of labour in the market. As the dramatic increase of transaction efficiency driven by the development of ICT, big data, high-speed railway, transportation systems and logistics systems, the 
room for them to organise division of labour is dramatically increasing as well. Under the same resource scarcity, a more efficient structure of division of labour means higher productivity.

Third, consumption patterns are also changing. As smart phones and internet become common, people's demands for goods and services are changing significantly. For instance, internet-based requirements for new, nonmaterial services are dramatically increasing. The change of consumption means a decrease in the scarcity of natural resources.

Fourth, the production model is shifting and the so-called third industrial revolution is emerging. In the future, manufacturing is likely to turn from a centralised and massive production model into a distributed and individual model. It is not impossible for countries with poor manufacturing capacities to leapfrog to the era of digital manufacturing. And traditional agriculture promises to be a profitable business. When it comes to services, changes are also significant. For example, the internet-based revolution in educational models, such as Courser or Khan Academy, enables everyone to access to the best educational resources in the world. Thanks to the non-competitive nature of educational resources, the cost does not increase with the rise in the number of users. This internet-based educational model provides opportunities for building the knowledge-based economy, which is conducive to improvement in the environment.

The changes elaborated above are just part of the comprehensive changes that are happening. A striking feature of the changes is that they all have the effect of decreasing scarcity of resources and emitting less pollution per unit of output. That means that green growth cannot be narrowly understood as the stories of new energy, or a few cutting-edge high technologies. In fact, green growth is the most profound and comprehensive transformation of development mode since the Industrial Revolution, and the potential for green growth is much bigger than many thought. Nonetheless, the opportunities of green growth can only be comprehended if its nature is properly understood.

\section{Opportunities of Green Growth in China}

Green growth is likely to not only be a new engine for economic progress, but also to improve the quality of growth in China (WB/DRC 2013).

First, 'going green' can be a new source of economic growth. In the process of green transformation, the upgrading of traditional industries and the emergence of new green industries, including green services, provide new drives for 
economic progress. Moreover, it will consume fewer resources, emit less carbon, and become more environmental friendly per unit of output. The sources fall into three categories.

\section{Green Transformation of Traditional Sectors}

Many existing techniques and management patterns will not only help in conserving energy and reducing pollution, but also increasing profit. For instance, according to estimates by McKinsey \& Company (2009), installing light-emitting diodes(LEDs) for lighting in buildings could generate US $\$ 25$ billion in annual financial savings by 2030, compared to business as usual (measured in 2009 dollars). Improving passive heating through design modifications could provide another US $\$ 6$ billion. Together, the potential for direct savings through efficiency gains in China could be as high as US\$65 billion per year by 2030, if the full technical and economic potential of these so-called 'no-regret' options can be realised (WB/DRC 2013: 224).

Though these figures are estimates only, it is certain that traditional sectors have great potential for 'going green'. Though the effects of upgrading traditional sectors are not as dramatic and revolutionary as the effects of a few cutting-edge green technologies, its potential for 'going green' is huge due to its massive scale.

\section{Expansion of Emerging Green Industries}

Green industries involve all industries with low levels of pollution and greenhouse gas emissions. In the narrow sense, it refers to industries represented by clean energy sectors, mainly solar energy, wind energy and related device manufacturing and electric vehicles. Cost reductions and technological progress in renewable energy technologies in China have exceeded expectations, mostly due to a massive scaling-up in the industry. In renewable energy, the cost of both wind energy and solar photovoltaic (PV) equipment has decreased dramatically during the past five years (Feng \& Wang 2011).

\section{Expansion of Service Sectors}

Ecosystem service has become a big industry in some countries. Instead of making money through selling wood, farmers in some economically poor regions in China now make their living by providing ecosystem services. There are also other new green services, such as carbon asset management, carbon trade, energy performance management, environment assessment, climatic-risk disclosure, and integrated solutions for urban management. Certainly, most traditional service industries are green, and China has great potential in these sectors. 
Second, green growth can improve the quality of growth in China. The benefits for improving the environment are numerous - it not only enhances people's welfare and health conditions, but also mutually reinforces economic growth. Japan's experience also shows that, even under stringent environmental policies, its economy has been expanding more rapidly without environmental policy. Moreover, preventive environmental policy is even more economically rewarding (Kobayashi 2011).

Green growth also promises to solve other problems, such as energy security, urban livability, and agricultural output augmentation. Rapid energy consumption will affect China's energy security. It's predicted that, under current energy policies, China is likely to be dependent on imports for 75 per cent of its petroleum (making it the world's largest oil importer) and 50 per cent of its natural gas requirements by 2030 (WB/DRC 2013). Traffic congestion and energy consumption can be relieved by strengthening land management for higher efficiency of use. Agricultural output can be enhanced by impeding the decrease of land fertility and water pollution.

\section{Advantages of China in Achieving Green Growth}

China has lots of advantages in promoting green growth (see WB/DRC 2013). Fundamentally, green growth relies on market forces. Nonetheless, the prerequisite for the market to function well in promoting green growth is that the government should play its role in reducing carbon emissions and forcefully protecting the environment. The determination of senior levels of government on green growth and effective decision-making mechanisms, as well as strong government execution, will, therefore, play a vital role for the country to promote green growth. In this respect, China has evident strengths. The Chinese Government has the ability to mobilise action on high priority issues and its senior leaders have already reached a consensus on the importance of green development. This commitment is also evident in the Work Program to Control Greenhouse Gas Emissions during the 12th five-year plan, in which the State Council makes clear that 'addressing climate change will accelerate economic restructuring and the reform of economic development, driving forward the opportunities of the next industrial revolution'. The following paragraphs outline an additional seven advantages that benefit China in seeking green growth. 
First, China enjoys the advantage of being a relative latecomer to industrialisation. Its relatively lower level of development gives it a room to meet its new demands by developing green productivity and infrastructures. In contrast, developed countries will have to shut down some old capacities in order to go green.

Second, a large domestic market allows China to scale-up its green sectors. As the world's second largest market, China is likely to embrace an even more rapid market expansion of green products and services over the next few years, since its domestic green market is still underdeveloped. As expected, the income of urban and rural residents will double by 2020, based on the 2010 level.

Third, China enjoys the advantages of abundant capital (including human capital) available to invest in its green sectors. Thanks to its high investment ratio, green industries are set to grow rapidly. In respect of human capital, in the 20 years to come, about 200 million Chinese students will graduate from school, providing green innovation with sufficient human resources (WB/DRC 2013).

Fourth, there is a huge potential for traditional sectors that are burdened with overall low efficiency to upgrade techniques. For example, it's promising to use coal in a clean way, given coal accounts about 70 per cent of total energy consumption in China.

Fifth, China has the potential to avoid lock-in effects of higher levels of nongreen urbanisation. Twenty years from now, China's urbanisation level will rise from 51 per cent to 65 per cent, with over 200 million farmers swarming into cities. That will bring about great potential for economic growth, and thereby green city construction will benefit from the avoidance of the lock-in effect.

Sixth, China has an abundant natural endowment of resources for clean energy including wind power, solar power, shale gas and methane, making the country less dependent on fossil fuels and freer to improve its energy security.

Lastly, with all of the above advantages, coupled with its strong manufacturing capacity as a 'world workshop', China is likely to be a major destination for commercialisation of green technologies worldwide. Green technologies can be produced, applied and sold in China no matter wherever they are invented. Green growth, therefore, not only provides opportunities for China, but also means opportunities for the rest of the world. 


\section{Unprecedented Challenges and Unfinished Structural Reforms}

\section{Unprecedented Challenges for China}

China has achieved remarkable progress in promoting green growth. At the moment, China is the world's largest renewable resources investor. Nonetheless, China has not given full play to its potential given that enormous challenges are yet to be overcome. The changes discussed in this chapter have two prominent features that act as an unprecedented challenge to China's current development model.

First, the changes challenge China's traditional government-led development model. Green growth that is based on ICT, big data and renewable resources is highly decentralised. Different from the conventional model driven by large and medium-sized companies, green growth is driven by networked small and medium enterprises (SMEs). This means the government-led model is not viable for green growth.

Second, the changes challenge the imitative model of China. As a catchingup economy, China has been copying Western economic models and is not innovatively creating its own. In the past all the models of economic organisation, industrial structure, and business models in industrial countries have been copied in China. Now, all of a sudden, green growth has become a global trend. In the case of green growth, China stands at the same frontier as the United States and Europe.

China must conduct in-depth reforms to meet the two challenges above. In essence, green growth is an institutional competition in which only those with creativity can stand out. Facing this pressing challenge, it is impossible for China to adopt a 'wait and see' strategy. Waiting for a mature green model to be developed by Western countries first in order to be copied by China is problematic.

There is no way for China to achieve modernisation with the existing unsustainable growth model (WB/DRC 2013). Furthermore, China would stay on the back foot even if it accomplished modernisation with the current model. Of course, higher prices must be paid in transferring to a green growth model from a lock-in status. China takes a long time to develop new industrial chains and business models and, in terms of green growth, early action is rewarding. For China, the window of opportunity is no longer than the next 20 years as this is the key period for China to become a high-income society. Once the window of opportunity is missed, China will have to pay a high price to in 'going green'. 


\section{Necessary Structural Reforms}

Enormous transitions are required for China to achieve green growth. The biggest barrier for China to promote green growth is not from capital or technology, but the failure in building effective market mechanisms. The following are the major reforms that need to be undertaken:

Type I reforms: transformation of government function. The biggest barrier is that the traditional pattern of governmental behaviour contradicts the inherent requirements of green growth. Green growth requires not only the development of green industries, but also that those industries be developed in a green way. Taking new energy industries as an example, China is now the largest new energy investor in the world. The so-called green industries, however, are not developed in a green way, but in a traditional high-pollution and high-emission way. Enjoying strong government support, those industries expanded too fast without sufficient innovation and risk resistance ability. Besides, domestic demand has not yet been fully developed. In the case of PV, 95 per cent of products were exported in 2012. The problem lies in the defective market economy and distorted government behaviour, which is a result of the existing GDP-oriented official performance evaluation system, and of the existing fiscal and tax system.

Type II reforms: consolidating the market economy. The most urgent reform related to green growth should be improving the pricing mechanism for resource products such as coal, electricity, gas and water to fully reflect their external hazard to the environment and health in exploitation, production and use, as well as to reflect their scarcity in the market. Meanwhile, the government should review and gradually remove the subsidies to the producer of resources and fossil fuel, and charge high royalties on natural resources (mineral products, oil, natural gas, shale gas, and coal bed methane) occupied by state-owned enterprises (SOEs). Moreover, it is also very important to break the monopoly and stimulate private investment in the resources and energy sector.

Type III reforms: tougher policies and regulations on emission reduction and environment protection. The prerequisite for green growth is that the government must control carbon emissions and forcefully protect the environment so as to reduce the social and coordination cost to the whole society, thereby allowing the market to function well. This kind of governmental action is actually a new public service and is consistent with the market economy. The government is obliged to make strict emission and environment policies. Moreover, the government should introduce flexible and effective policy implementation mechanisms, including market-based emission reduction mechanisms (e.g. emissions trading scheme, ETS). 
In terms of environmental protection, it is necessary to introduce marketoriented incentive mechanisms such as well-defined water rights that are enforced, ownership of land and forest, a water-rights market, emission-trading scheme, and land-use quota-trading markets. For example, farmers in poor areas would actively enhance the efficiency of land use if additional farmland quotas could be sold to developed regions. Another beneficial mechanism would be the improvement and expansion of Payments for Ecosystem Services (PES), especially in poor regions. The farmers would have the motivation to improve and protect the local ecological environment if they could get sufficient economic returns through providing ecosystem services.

In terms of laws and regulations, government should introduce tough standards for environmental protection, carbon emissions and energy efficiency improvement. For instance, introduction of a clean air Act; new standards for lighting and high fuel-efficiency for vehicles; new national standards for urban design and energy efficiency and emissions from transportation; and, identifiable green standards and labelling for products, services and techniques for consumers. Some outdated regulations, such as limits to the production of low-speed electric vehicles, need to be revised.

Type IV reforms: offsetting the negative impacts of green growth. In addition to the institutional factors, the resistance to green growth also comes from its inevitable negative impact on some industries, regions and groups. Businesses that have benefited from traditional growth models are likely to have originally opposed the 'going green' strategy. Since the comprehensive green strategy needs to reshuffle the power of some ministries, and some of their interest might be affected, they may oppose green strategy. In addition, though green strategy would bring prosperity in the long run, it may challenge some economic targets (e.g., industrial output targets) in the short run. To offset the negative impact of green growth, an incremental reform approach should be adopted, and some policy tools (e.g., subsidies and training programs for the affected individuals) should be put in place.

Type V reforms: fostering green industries. 'Going green' is a comprehensive and profound process. The government should employ various measures, including tax, finance, trade, standards and public investment, to foster the sources of green growth. For example, in the early stage, key green industries could be exempted from taxes for a limited period as part of the ongoing policy of structural tax cuts in China. In contrast, high-pollution, high-emission-and-resource products should be imposed with heavy taxes and gradually removed from the list of export tax rebates and limited for export. Meanwhile, the share of green products that enjoy rebates should be increased. 
Green enterprises should also be provided with preferential policies for loan, debt and financing. Also, green standards should be introduced in government procurement.

\section{Conclusion}

Green growth, as the most profound and comprehensive transformation of the development model since the Industrial Revolution, represents great opportunities, as well as formidable challenges for China. To seize the opportunities, we first need to understand what green growth really means. The opportunities of green growth cannot be seen in traditional industrialised thinking. We should understand the concept of green growth in new thinking and discuss it in the dynamic context of the new technology revolution.

China has many unique advantages in promoting green growth. At the same time, there are some major obstacles to be removed by deepening structural reform. The biggest barrier is not in the form of investment or technology, but instead in the form of institutional barriers. To seize the opportunities, the barriers should be overcome through structural reform. Moreover, the decentralised green growth model substantively challenges the traditional government-led centralised development model. For China, its strategic period of opportunities only exists in the coming 10 to 20 years. Once this opportunity period has passed, China will have to pay a much higher price for 'going green'.

\section{References}

Coase, Ronald, 1937, 'The nature of the firm', Economica, vol. 4, no. 16, pp. 386-405.

Feng F. \& Wang, J., 2011, 'Focusing on New Developments in Wind and Solar Power', Working Report 88, Development Research Center of the State Council, P.R. China.

Kobayashi, H., 2011, 'Basics of Eco-Business: Mutually Supportive Relationship between the Environment and the Economy', paper presented at the third international forum for sustainable Asia and the Pacific, Institute for Global Environmental Strategies, Yokohama, 26-27 July.

Maddison, Angus, 2001, The World Economy: A Millennial Perspective, OECD Publishing, Paris.

McKinsey \& Company, 2009, ‘China's Green Revolution: Prioritizing Technologies to Achieve Energy and Environmental Sustainability', http://www.mckinsey.com. 
Smith, Adam, 1776, An Inquiry Into the Nature and Causes of the Wealth of Nations, 1976 ed., E. Cannan, University of Chicago Press.

World Bank \& Development Research Center of the State Council, P.R. China, 2013, China 2030: Building a Modern, Harmonious, and Creative Society, Washington, DC.

Yang, Xiaokai, 2001, Economics: New Classicial Versus Neoclassical Frameworks, Blackwell Publishers Inc.

Young, Allyn, 1928, 'Increasing Returns and Economic Progress', The Economic Journal, vol. 38, pp. 527-42. 